\title{
Proceeding
}

Supplementary Issue: Summer Conferences of Sports Science. Costa Blanca Sports Science Events, 25-26 September 2020. Alicante, Spain.

\section{Dual role of scaffolding on motor-cognitive development in early childhood education}

\author{
PATRIZIA TORTELLA ${ }^{1} \triangle$, ROSARIA SCHEMBRI ${ }^{2}$, ANDREA CECILIANI ${ }^{3}$, GUIDO FRANCESCO \\ FUMAGALLI ${ }^{4}$ \\ ${ }^{1}$ Free University of Bolzano, Italy \\ 2 University of Enna "Kore", Italy \\ 3University of Bologna, Italy \\ ${ }^{4}$ University of Verona, Italy
}

\begin{abstract}
The link between motor and executive function (EF) development is unclear. To test whether learning difficult motor task drives EF development, we measured EF changes in 5-year-old children from 3 kindergartens in north-eastern Italy engaged in a specific motor program including a difficult motor task (walking on unstable bar). One-hundred children divided in 2 groups participated for 1 hour/week for 10 weeks: Group A was supported by a teacher and group B no. The capacity to perform the difficult task was assessed at the beginning and end of the study; the children able (Groups A1 and B1) or unable (Groups A2 and B2) to perform the task at the Pre-test were similar in the 2 groups. To assess EF, the day/night test (Gerstadt et al., 1994) was used. Dynamic balance results. Time at spring bar: Group A pre 69.2 post 29.6 - Group B pre 71.8 post 48.8. EF results. Group A1 pre 4.90 post 2.71 - Group B1 pre 3.62 post 3.54. Group A2 pre 4.64 post 1.22 - Group B2 pre 5.30 post 3.55. Conclusions. Teacher support significantly promoted improvement of motor skill; teacher's scaffolding significantly promoted EF development in children with initial low motor competence only.

Keywords: Motor competence; Executive functions; Kindergarten; Playground; Scaffolding; Physical activity.

\section{Cite this article as:}

Tortella, P., Schembri, R., Ceciliani, A., \& Fumagalli, G.F. (2020). Dual role of scaffolding on motor-cognitive development in early childhood education. Journal of Human Sport and Exercise, 15(4proc), S1407-S1417. doi:https://doi.org/10.14198/ihse.2020.15.Proc4.37

Corresponding author. Free University of Bolzano, Italy.

E-mail: patrizia.tortella@gmail.com

Abstract submitted to: Spring Conferences of Sports Science. Costa Blanca Sports Science Events, $19-20$ June 2020. Alicante, Spain.

JOURNAL OF HUMAN SPORT \& EXERCISE ISSN 1988-5202

(c) Faculty of Education. University of Alicante

doi:10.14198/jhse.2020.15.Proc4.37
\end{abstract}




\section{INTRODUCTION}

Executive Functions (EFs) are cognitive processes that can be modified and trained (Kovacs \& Mehler, 2009) throughout a person's life. Some authors (Diamond, 2013; Miyake et al., 2000) consider inhibitory control, working memory and cognitive flexibility the major functions, from which the minor ones are generated. Inhibitory control allows to act wisely, without responding impulsively to a stimulus. The working memory allows to remember information and use it during a different task, relating it to the new situation (Baddeley $\mathrm{e}$ Hitch, 1994). Cognitive flexibility is the ability to flexibly adapt to new demands (Kiesel et al., 2010).

The reasons why EFs have attracted much interest are multiple. It has been shown that high level of EF are associated to several beneficial effects including quality of life, levels of happiness (Moffit, 2012) and school success, from preschool to university (Borella et al., 2010; Nicholson, 2007). High levels of EF appear to be associated to good reading and math skills (Morrison et al., 2010; Blair and Razza, 2007); they are also fundamental for getting and keeping a job, career advancement (Bailey, 2007), weight control (Crescioni et al., 2011), making friends (Huges and Dunn, 1998), resisting substance abuse (Miller et al., 2011). Finally, levels of EFs are better than socioeconomic status or IQ in predicting socio-economical achievement and status, wealth, health (Moffitt et al., 2011, 2012).

EFs can be trained, especially in children and young adults (Diamond \& Ling, 2016) and numerous studies have investigated the relationship between cognitive processes, physical activity (PA), and motor development (Singh et al., 2019, Tortella \& Fumagalli, 2017, Diamond \& Ling, 2016). Recently, Diamond A. \& Ling (2020) have published a major review of this topic in which they examined methods and results in 193 studying the relationship between physical activity (PA) and executive functions (EFs).

Different set ups have been used to foster EF development in children, adults and masters. The methods included computerized and non-computerized cognitive training, neuronal feedback, school programs and activities, mindfulness practices, body experiences and more. The methodological approach that appeared to be the most effective for EF development was a specific combination of conscious approach and PA, namely traditional taekwondo and t'ai chi (Trulson, 1986; Lakes \& Hoyt, 2004). Positive but less extensive results were obtained by good school curricula and non-computerized cognitive training. Interaction with the educator seemed to play an important role for the development of EFs; accordingly, non-computerized cognitive training methods (which require assistance by the educator) were more effective than computerized ones.

A further element that may link EF and PA development is the task difficulty. Indeed, increasing levels of task difficulty associated with high levels of cognitive engagement appear to promote development of both motor skills and executive functions (Kramer \& Erickson, 2007; Davis et al, 2011). In condition of challenging and difficult task, a child may undergo frustration if repeated trials are unsuccessful. As pointed out by Vygotsky, there are conditions where adults/friends may help the subject to scale to a level above his or current capabilities. The condition is defined as the "Proximal Development Zone", (Vygotsky, 1986; Davis et al., 2011), i.e. the condition when the subject is facing a difficult task that may leave frustration or can be overcome when he/she is "scaffolded"/helped by an experienced partner or an adult. Reaching a goal and overcoming a problem has impact on self-confidence This is a condition favourable to the development of motor skills and of positive perception of his/her own capabilities. In the field of PA, positive self-perception is a driving force for development of motor competences as it stimulates commitment to the exercise which, in turn, promotes motor competence development (Stodden et al., 2008, Fischetti et al., 2020a, 2020b, Russo et al., 2019). 
In this study we have tried to address the issues raised by Diamond \& Ling (2020) on factors linking PA to EF development by organizing a condition where progression in motor competence is monitored for a motor task organized in "Zone of Proximal Development" for 5 years old children. Under this condition, the adult intervention (scaffolding) can be easily manipulated and the effects on motor and EF development evaluated.

Accordingly, we have characterized difficult motor task presented to pre-school children and we have studied the impact of a teaching solution whereby an adult (educator) provides "scaffold" to the child. Preliminary data indicate that motor learning and development of motor competence was strongly fostered by the scaffolding procedure (Tortella et al., 2016). We are now using this experimental setup to investigate the relationship between development of a motor competence and of EFs. In details we tried to answer to the following questions: 1 - is scaffolding by the educator an efficient tool for increasing motor competence and EF levels in children? Are the effects of scaffolding for the motor task equally effective on development of motor competence and EF levels?

\section{METHODS}

The project was evaluated by the Scientific Committee of "Laboratorio 0246", the Association that owned the site where we did the research. The Scientific Committee approved the study and verified the adherence to the principles of the Declaration of Helsinki. Written informed consents were obtained from the parents before the children attended the study. Authorizations were obtained from the directors of the schools and from the teachers involved. Before asking the adults to sign the authorizations, an extensive written description of the goals, limits, risks of the study, methods used, and activities performed was given.

Field permission of the study was granted by: A.S.D. Laboratorio 0246-Strada del Nascimben 1/B 31100 Treviso Phone:+39 0422324310 Fax: +39 0422324311 Email: info@0246.it; http://www.0246.it/. Laboratorio 0246 has made the playground available for research studies on child motor development. The Scientific Committee, who approved the study, has monitored the adherence to the principles of the Declaration of Helsinki throughout the study.

\section{Site}

This study was carried out at the playground Primo Sport 0246 located in "La Ghirada", a sport centre in Treviso, Northern Italy. The playground is a specific space designed to provide opportunities for practicing basic motor skills to children up to the age of six (Buzzavo et al., 2011). It is organized in 4 areas: manual skills area, mobility area, balance area and symbolic play area. Each area contains fixed equipment useful to promote the specific motor skills of the area (Figure 1).

\section{Participants}

One hundred 5 years old children were included in the study. They were from 3 kindergartens that were selected from a total of 23 kindergartens present in the area of Treviso because of the similarities in the socio-economic system and ethnic origin of the families.

Motor skills and EFs were tested before and at the conclusion of a training period. The training period consisted of 10 visits to the park, occurring once a week for 10 consecutive weeks. The 100 children were divided in 2 Groups, A and B. Children of Group A played for 30 min under the guidance of trained adults (structured play) followed by additional 30 min when they could play as they wanted (free play). During the 30 min of structured play, the children spent 10 minutes in the manual skill area, 10 min in the mobility area and $10 \mathrm{~min}$ in the balance area, where they were also engaged with the very difficult tool, the "elastic bar" 
(Figure 2). For the time spent with structured activities, children were further divided in small groups of 5-6 units. In each area the activities of the children were directed by specifically trained instructors. Instructor scaffolded children on demand; at the elastic bar, the scaffolding had been defined in detail scaffolding on the "elastic bar" was specifically defined and is described below. After the 30 min of structured play, the children spent the remaining 30 min in modality "free play".

Children of group B were in "free play" modality for the entire hour spent at the park.

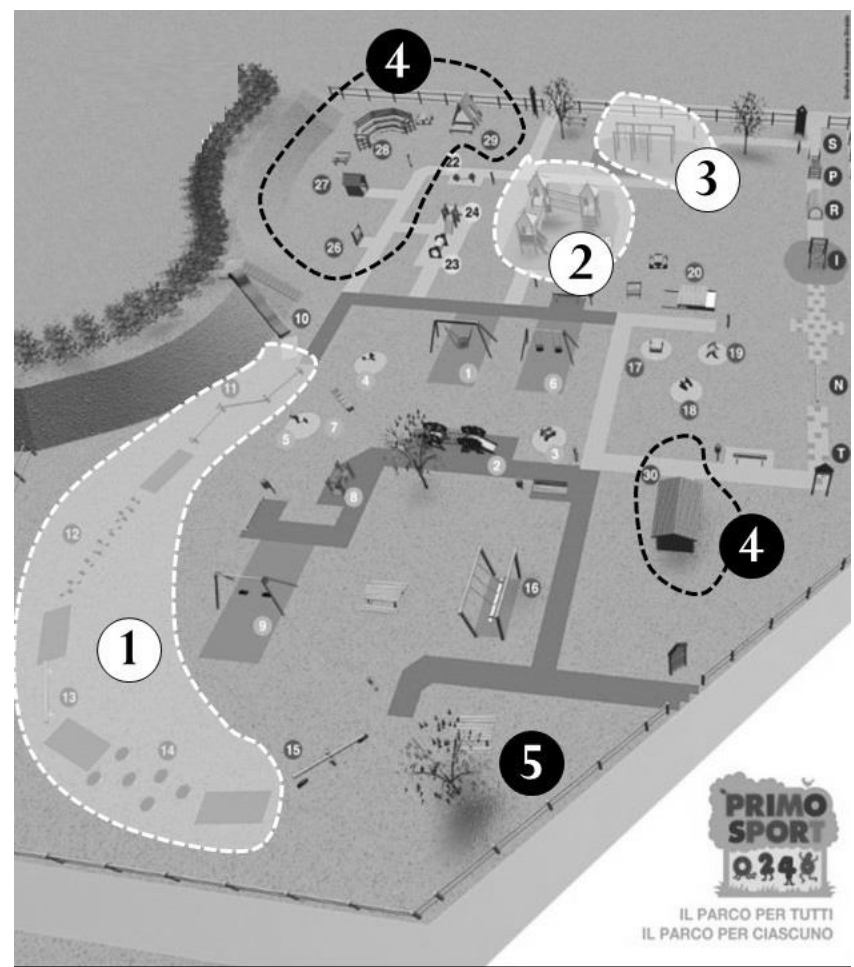

Figure 1. The playground Primo Sport 0246, Treviso and the areas: 1-Balance are; 2-Mobility area; 3Manualità area.

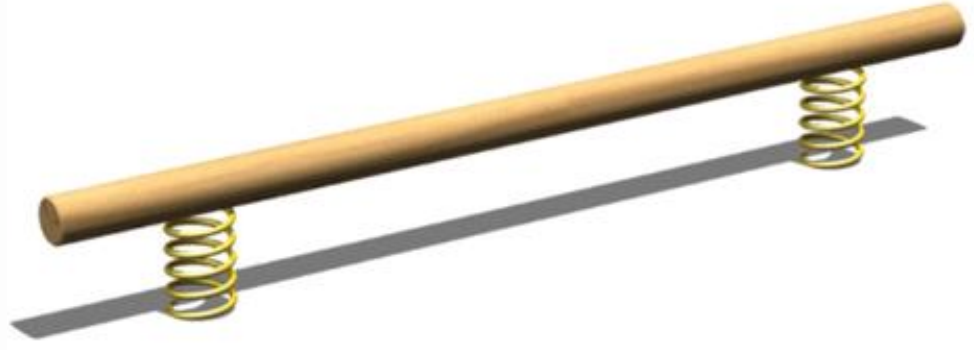

Figure 2. The elastic bar: $3 \mathrm{~m}$ length, $40 \mathrm{~cm}$ height; the springs make the bar very unstable.

\section{The "difficult" motor task}

The child was asked to get on the bar and walk to the other side without falling. If the child fell, he had to go up again on the bar from the drop point and then continue his path. We measured time to complete the task and number of errors at the beginning and at the end of the training period (10 weeks). 


\section{Scaffolding}

The instructor told the child that if he wanted to be helped to climb the bar he could lean on his arm (see figure 3). The child could choose what to do. Once he was on the bar, he could start walking to the opposite extremity of the bar and no support or help was offered at that moment. When the child was about to fall from the moving bar, the instructor instructed vocally the child by saying: "If you feel like falling, let me see a beautiful jump!" After the jump, the child had to climb up on the bar from that same point and scaffold was offered as at the beginning. Each child was followed on an individual level.

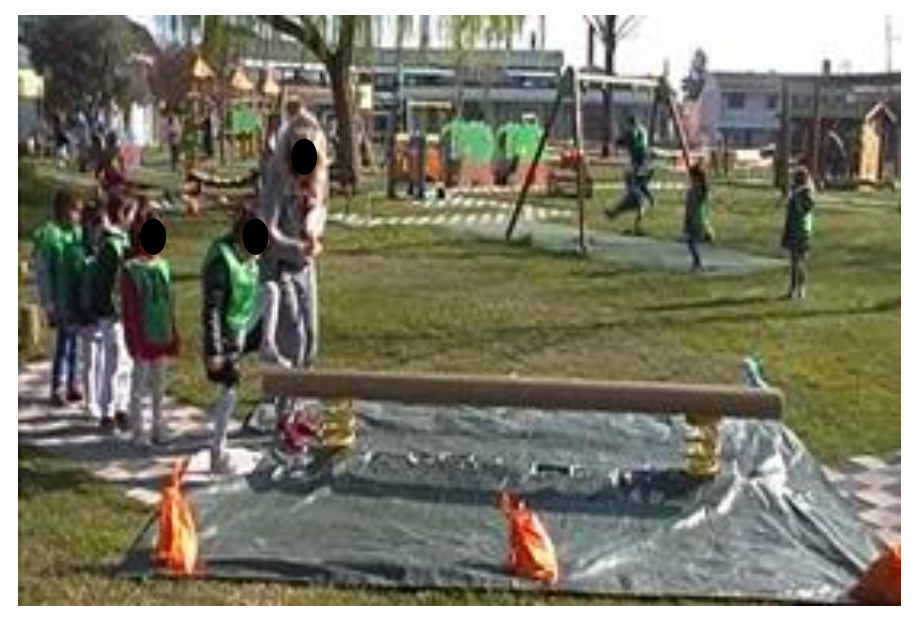

Figure 3. Child climbing the elastic bar; note that the instructor is offering her arm to help the child (scaffolding).

\section{RESULTS}

As shown in Table 1, a significant improvement of the dynamic balance motor competence was observed in the group of children who were exposed to structured activity, i.e. were scaffolded by the instructor during the execution of the difficult task. (Group A). The difference in the time needed to walk along the unstable bar for the children of the free-ply group (group B, not being scaffolded by the instructor) was not statistically significant.

Children who were trained by the instructor (structured activity) showed a significant increase in dynamic balance competence to the bar with springs.

Table 1. Motor test.

\begin{tabular}{lcc}
\hline & PRE & POST \\
\hline Group A & $69.2 \pm 3.8$ & $29.6^{* *} \pm 2.0$ \\
Structured activity + free play & $71.8 \pm 5.7$ & $58.8 \pm 3.9$ \\
Group B & Free play only &
\end{tabular}

Data are secs to walk the entire unstable bar. Time lost for falling and climbing again is included (mean \pm SE). Group A: structured activity; Group B: free-play only. Measurements were taken before (pre) and at the end (post) the 10 weeks training period. **: $t$ students $p<.01$. 
The data from the Day \& Night test revealed that structured activity had an impact on the performance on the cognitive test. Indeed, a significant reduction of errors was seen in the children of Group A while the difference was not significant for children of Group B (free play only). However closer analysis of the data revealed that the intensity of the effect of the training on performance on the EF test was also related to the initial level of motor skill of the child (Table 2). Accordingly, the population of children of each group was further subdivided in two aggregates ( 1 and 2 ) depending on the initial capacity to walk along the axis (more than 3 falls during the walking: beginner; less than 3 falls: expert). In table 2 we report the results with the entire population subdivided in 4 groups where $A$ indicates participation to structured activity and $B$ to free-play only, 1 : EXPERT, i.e. sufficient initial motor skills, 2: BEGINNER, i.e. minimal initial motor skill for the task.

Table 2. Day \& Night test (executive functions).

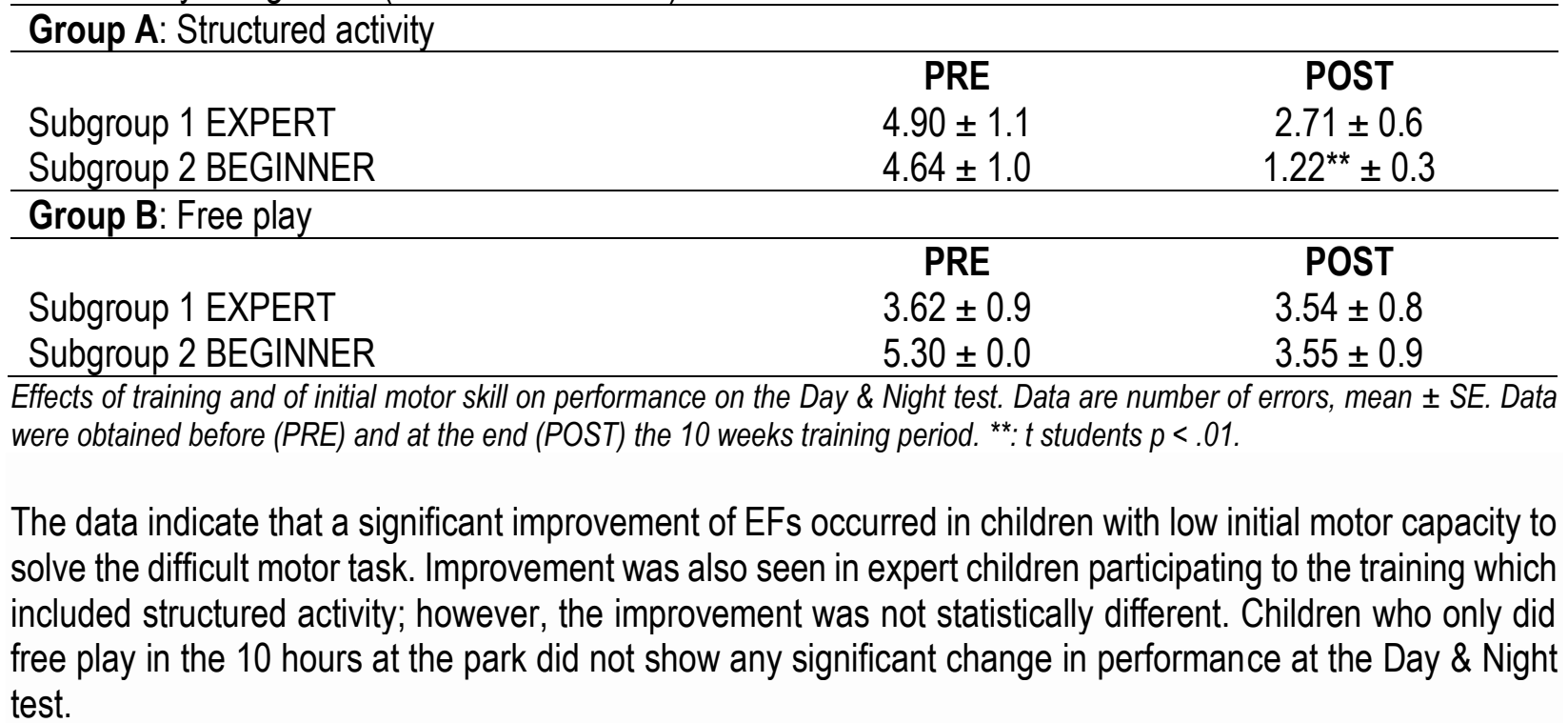

\section{DISCUSSION AND CONCLUSION}

In this study we have analysed the possible relationships between PA and EF. To this aim we established a simple experimental condition where development (increase) of motor competence and of executive functions could be followed in parallel and manipulated by introducing two potentially different training procedures: structured activities with scaffolding and free-play.

PA has multiple effects on the physical and psychological well-being of children; non adequate levels of PA are considered a relevant risk factor for obesity and number of chronic non-communicable diseases that have a negative impact on the health of the child and of the future adult (Rennie et al., 2005; Singh, 2008; Rasmussen et al., 2000). EFs also have a relevant impact on the quality of life of children and adults (Diamond, 2014) and a great effort has been done to find conditions that may support EF development by performing health-inducing PA. Despite years of research, no clear relationship between development of EF and type, level and quality of physical exercises has been established.

On the other hand, PA and EF share common features. Levels of EFs can be lowered by stress, sadness, loneliness, poor health, whereas social support, joy, physical health, satisfaction of emotional and physical needs have the opposite effect (Arnsten, 1998; Cacioppo e Patrick, 2008; Gable \& Harmon-Jones, 2008; Etnier et al., 2006). Self-confidence and enjoyment during activities are fundamental elements for the optimal 
functioning of mental processes (Bandura, 1994). The child who thinks that efforts can help personal improvement and that mistakes are learning opportunities, is in the best conditions to improve cognitive skills and motor skills as well (Murphy \& Dweck, 2010, Bandura, 1994). Intensity, duration and speed are key factors for physical training (Shephard, 1968, D'Elia, 2019, 2020; Sgrò, 2018, 2020); as for EFs, personal satisfaction and positive self-perception promote greater commitment to the exercise, which promotes motor competence development and maintenance of health-conditioning fitness levels (Stodden et al., 2008).

In both EF and motor development, difficulty of the task associated with high levels of cognitive engagement promote development (Eccles \& Harold, 1991; Kramer \& Erickson, 2007; Davis et al, 2011).

A difficult task can be a source of frustration that has a negative impact on development of either EFs or motor competences. The issue has been addressed by Vygotsky years ago who introduced the concept of "Proximal Development Zone", i.e. the level of task that is above his or her current capabilities and that he or she can only succeed if helped by an experienced partner or an adult (Vygotsky, 1986; Davis et al., 2011). This is a condition favourable to the development of motor and cognitive skills.

Successful experiences, thanks to the adult's scaffolding promote joy and pride in the child and development of skills. As indicated by Diamond, these are conditions that stimulate EF development, and stimulate positive self-perception of motor skill and motor development (Stodden, 2008).

In a previous study at the playground Primo Sport 0246 in Treviso (Tortella \& Fumagalli, 2014, 2016, 2019) we have shown that a training on a very difficult motor task in the proximal development area has promoted development of motor skills only if associated to a teaching methodology related to the concept of "Proximal Development Zone".

In this study we have further investigated this issue and have examined the effects of the same teaching intervention on development of EFs measured by responses of children in the Day \& Night test.

The results confirm that overcoming the difficulties of a motor task (for example, by training) may have an impact on development of EF as suggested by comparing the results of groups $A$ and $B$ of the present study. The group of children who were left playing as they wanted (free play, group B) did not solve the motor problem and showed no increase of either motor or EF competence. The scaffolding procedure established by the teacher (structured activity, group A) had a significant impact on development of motor skill and an increase in EFs that was more abundant and highly significant in the children that started their training experience with a low level of the skills required for performing the difficult balance task (Group A2).

On the other hand, introduction of a difficulty level requiring teaching in the "Proximal Development Zone" may have an impact on development of EFs as well. These data confirm the hypothesis of Diamond \& Ling (2020) that and that PA per se may not have direct effects on EFs development and highlight the importance of the teaching methodology used by the teacher as one of the determining factors in the development of EFs during performance of PAs (Tortella \& Fumagalli, 2017; Diamond, 2000, 2014; Pietarinen, Soini, \& Pyhalto, 2014; Li \& Lerner, 2012).

Our results also highlight that other factors participate to the linkage of the triangle: teaching, PA and EF. When analysing the results of the "scaffolded" group (Group A), we observed that the impact of the learning of the motor skill on EF development was more pronounced when the initial motor skills were low (beginner 
of Group A). Learning a new motor task engages areas of the brain, such as the prefrontal cortex that are also related to expression of the EFs (Werchan et al., 2016).

In conclusion, our results support the hypothesis that PA and EFs can be linked together when a teacher adopt a strategy for organizing the motor activities that takes into account the multiple factors (initial motor skill of the child, difficulty of the motor task, procedure for scaffolding) that may strengthen or loosen the link between PA and EF development.

\section{ACKNOWLEDGMENTS}

We thank A.S.D. Laboratorio 0246 and Verdesport for local organization, help and support, the schools of Treviso, CONI of Treviso, for participation to the study. This research was supported by Comitato Olimpico Nazionale Italiano CONI-Treviso and A.S.D. Laboratorio 0246, Treviso, Italy. We particularly thank Eleonora Magri for her precious and constant support in the organizational part of the research.

\section{REFERENCES}

Arnsten, A.F.T., 1998. The biology of being frazzled. Science (New York, N.Y.), 280 (5370), 1711-1712. https://doi.org/10.1126/science.280.5370.1711

Baddeley, A.D., Hitch, G.J., 1994. Developments in the concept of working memory. Neuropsychology, 8, 485-493. https://doi.org/10.1037/0894-4105.8.4.485

Bailey, C.E., 2007. Cognitive accuracy and intelligent executive function in the brain and in business. Ann. N.Y. Acad. Sci., 1118, 122-141. https://doi.org/10.1196/annals.1412.011

Bandura, A., (1994). Self-efficacy. In V. S. Ramachaudran (Ed.), Encyclopedia of human behavior Vol. 4 (pp 71-81). New York, NY, Academy Press. Reprinted in H. Friedman (Ed.) 1998. Encyclopedia of mental health, San Diego, CA, Academic Press.

Blair, C., Razza, R.P., 2007. Relating effortful control, executive function, and false belief understanding to emerging math and literacy ability in kindergarten. Child Dev. 78, 647-663. https://doi.org/10.1111//.1467-8624.2007.01019.x

Borella, E., Carretti, B., Pelgrina, S., 2010. The specific role of inhibition in reading comprehension in good and poor comprehenders. J. Learn. Disabil. 43, 541-552. https://doi.org/10.1177/0022219410371676

Buzzavo, G., Da, Dalt, L., Durigon, V., Fumagalli, G., Maffeis, C., Moghetti, P., et al., 2011. Surroundings and activities just right for growing up well. Milano, Edizioni Libreria dello Sport. http://www.0246.it

Cacioppo, J., \& Patrick, W., 2008. Loneliness: Human Nature and the Need for Social Connection., New York, NY: W. W. Norton \& Co., Inc.

Crescioni, A.W., Ehrlinger, J., Alquist, J.L., Conlon, K.E., Baumeister, R.F., Schatschneider, C., Dutton, G.R., 2011. High trait self-control predicts positive health behaviors and success in weight loss. J. Health Psychol. 16, 750-759. https://doi.org/10.1177/1359105310390247

Davis, C.L., Tomporowski, P.D., McDowell, J.E., Austin, B.P., Miller, P.H., Yanasak, N. E., ... Naglieri, J.A., 2011. Exercise Improves Executive Function and Achievement and Alters Brain Activation in Overweight Children: A Randomized Controlled Trial. Health Psychology, 30(1), 91-98. https://doi.org/10.1037/a0021766

D'Elia, F., 2019. The core curriculum of university training to teach physical education in Italy, Journal of Physical Education and Sport, 19, 1755-1758. 
D'Elia, F., 2020. Teachers' perspectives about contents and learning aim of physical education in Italian primary school, Journal of Human Sport and Exercise, 15 (Proc2), S279-S288. https://doi.org/10.14198/ihse.2020.15.Proc2.19

Diamond, A., 2013. Annual Review of Psychology, 64(1), 135-168. https://doi.org/10.1146/annurevpsych-113011-143750

Diamond, A., \& Ling, D.S., 2020. Review of the evidence on, and fundamental questions about, efforts to improve executive functions, including working memory. In J. Novick, M.F. Bunting, M.R. Dougherty \& R. W. Engle (Eds.), Cognitive and working memory training: Perspectives from psychology, neuroscience, and human development, 143-431. New York, NY, Oxford University Press. https://doi.org/10.1093/oso/9780199974467.003.0008

Diamond, A., \& Ling, D.S., 2016. Conclusions about interventions, programs, and approaches for improving executive functions that appear justified and those that, despite much hype, do not. Developmental Cognitive Neuroscience, 18, 34-48. https://doi.org/10.1016/i.dcn.2015.11.005

Diamond, A., 2000. Close interrelation of motor development and cognitive development and of the cerebellum and prefrontal cortex. Child Dev., 71, 44-56. https://doi.org/10.1111/1467-8624.00117

Diamond, A., 2014. Want to optimize executive functions and academic outcomes? Simple, just nourish the human spirit. Minnesota Symposia on Child Psychology, 37, 203-230. https://doi.org/10.1002/9781118732373.ch7

Eccles, J.S., \& Harold, R.D., 1991. Gender differences in sport involvement: Applying the Eccles' Expectancy-Value Model. Journal of Applied Sport Psychology, 3, 7-35. https://doi.org/10.1080/10413209108406432

Etnier, J.L., Nowell, P.M., Landers, D.M., \& Sibley, B.A., 2006. A meta-regression to examine the relationship between aerobic fitness and cognitive performance. Brain Research Reviews, 52 (1), 119-130. https://doi.org/10.1016/..brainresrev.2006.01.002

Fischetti, F., Cataldi, S., Di Terlizzi, P., Greco, G., 2020a. Multilateral methodology in physical education improves coping skills, resilience and physical fitness in drug addicts, Journal of Human Sport and Exercise, 15 (2), 367-379. https://doi.org/10.14198/hhse.2020.152.11

Fischetti, F., Latino, F., Cataldi, S., Greco, G., 2020b. Gender differences in body image dissatisfaction: The role of physical education and sport. Journal of Human Sport and Exercise, 15 (2), 241-250. https://doi.org/10.14198/jhse.2020.152.01

Gable, P.A., \& Harmon-Jones, E., 2008. Approach-motivated positive affect reduces breadth of attention. Psychological Science, 19(5), 476-482. https://doi.org/10.1111/j.1467-9280.2008.02112.x

Hughes, C., Dunn, J., 1998. Understanding mind and emotion: longitudinal associations with mentalstate talk between young friends. Dev. Psychol. 34, 1026-1037. https://doi.org/10.1037/00121649.34.5.1026

Kiesel, A., Steinhauser, M., Wendt, M., Falkenstein, M., Jost, K., Phillip, A., Koch, I., 2010. Control and interference in task switching-a review. Psychol. Bull., 136, 849-874. https://doi.org/10.1037/a0019842

Kovács, A.M., \& Mehler, J., 2009. Cognitive gains in 7-month-old bilingual infants. Proceedings of the National Academy of Sciences U.S.A., 106(16), 6556-6560. https://doi.org/10.1073/pnas.0811323106

Kramer, A.F., \& Erickson, K.I., 2007. Capitalizing on cortical plasticity: influence of PA on cognition and brain function. Trends in Cognitive Sciences, 11 (8), 342- 348. https://doi.org/10.1016/j.tics.2007.06.009

Lakes, K.D., \& Hoyt, W.T., 2004. Promoting self-regulation through school-based martial arts training. Journal of Applied Developmental Psychology, 25, 283-302. https://doi.org/10.1016/.appdev.2004.04.002 
Li, Y., \& Lerner, R.M., 2012. Interrelations of behavioral, emotional, and cognitive school engagement in high school students. Journal of Youth and Adolescence, 42, 20-32. https://doi.org/10.1007/s10964012-9857-5

Miyake, A., Friedman, N. P., Emerson, M. J., Witzki, A. H., Howerter, A., and Wager, T. D. (2000). The unity and diversity of executive functions and their contributions to complex "frontal lobe" tasks: a latent variable analysis. Cogn. Psychol. 41, 49-100. https://doi.org/10.1006/cogp.1999.0734

Miller, H.V., Barnes, J.C., Beaver, K.M., 2011. Self-control and health outcomes in a nationally representative sample. Am. J. Health Behav. 35 (1), 15-27. https://doi.org/10.5993/AJHB.35.1.2

Moffitt, T.E., 2012. Childhood self-control predicts adult health, wealth, and crime. In: Multi-Disciplinary Symposium Improving the Well-Being of Children and Youth, Copenhagen.

Moffitt, T.E., Arseneault, L., Belsky, D., Dickson, N., Hancox, R.J., Harrington, H., Caspi, A., 2011. A gradient of childhood self-control predicts health, wealth, and public safety. Proc. Nat. Acad. Sci. U.S.A. 108, 2693-2698. https://doi.org/10.1073/pnas.1010076108

Morrison, F.J., Ponitz, C.C., McClelland, M.M., 2010. Self-regulation and academic achievement in the transition to school. In: Calkins, S.D., Bell, M. (Eds.), Child Development at the Intersection of Emotion and Cognition. American Psychological Association, Washington, DC, 203-224. https://doi.org/10.1037/12059-011

Murphy, M.C., \& Dweck, C.S., 2010. A culture of genius: how an organization's lay theories shape people's cognition, affect, and behavior. Personality and Social Psychology Bulletin, 36, 283-296. https://doi.org/10.1177/0146167209347380

Nicholson, C., 2007. Beyond IQ: youngsters who can focus on the task at hand do better in math. Sci. Am. (March).

Pietarinen, J., Soini, T., Pyhältö, K., 2014. Student's emotional and cognitive engagement as the determinants of well-being and achievement in school. International Journal of Educational Research, 67, 40-51. https://doi.org/10.1016/i.jier.2014.05.001

Rasmussen, J.T., Rasmussen, M.S., and Petersen, T.E., 2000. Cysteines involved in the interconversion between dehydrogenase and oxidase forms of bovine xanthine oxidoreductase, J. Dairy Sci. 83, 499506. https://doi.org/10.3168/jds.S0022-0302(00)74909-5

Rennie, K., \& Jebb, S.A., 2005. Prevalence of Obesity in Great Britain. Obesity Reviews, 6(1), 11-12. https://doi.org/10.1111/j.1467-789X.2005.00164.X

Russo, G., Nigro, F., Raiola, G., Ceciliani, A. (2019) Self-esteem in physically active middle school students, Journal of Physical Education and Sport, 19, art. no. 295, pp. 1984-1988.

Sgrò, F., Barca, M., Schembri, R., \& Lipoma, M., 2020. Assessing the effect of different teaching strategies on students' affective learning outcomes during volleyball lessons. Journal of Physical Education and Sport, 20, 2136-2142.

Sgrò, F., Pignato, S., \& Lipoma, M., 2018. Assessing the impact of gender and sport practice on students' performance required in team games. Journal of Physical Education and Sport, 18, 497-502.

Shephard, R.J. (1968). Intensity, duration and frequency of exercise as determinants of the response to a training regime. Int. Z. Angew. Physiol. Einschl. Arbeitsphysiol. 26, 272-278.

Singh, A.S., Mulder, C., Twisk, J.W.R., van Mechelen, W., \& Chinapaw, M.J.M., 2008. Tracking of childhood overweight into adulthood: a systematic review of the literature. Obes Rev, 9(5), 474-88. https://doi.org/10.1111/j.1467-789X.2008.00475.x

Singh, A.S., Saliasi, E., van, den, Berg, V., Uijtdewilligen, Léonie, de, Groot, R.H.M., Jolles, J., Andersen, L.B., Bailey, r., chang, Y.K., Diamond, A., Ericsson, I., Etnier, J.L., Fedewa, A.L., Hillman, C.H., McMorris, T., Pesce, C., Puehse, U., Tomporowski, P.D., \& Chinapaw, M.M., 2019. Effects of physical activity interventions on cognitive and academic performance in children and adolescents: 
a novel combination of a systematic review and recommendations from an expert panel. British Journal of Sports Medicine,53, 640-647. https://doi.org/10.1136/bjsports-2017-098136

Stodden, D.F., Goodway, J.D., Langendorter, S.J., Roberton, M.A., Rudisill, M.E., Garcia, C., \& Garcia, L.E., 2008. A developmental Perspective on the Role of Motor Skill Competence in PA: An Emergent Relationship. Quest, 60, 290-306. https://doi.org/10.1080/00336297.2008.10483582

Tortella, P., \& Fumagalli, G., 2014. Difficult motor skill acquisition in 5 years old children can be modulated by educators. Science \& Sports, 29(Suppl), S49-50. https://doi.org/10.1016/j.scispo.2014.08.099

Tortella, P., \& Fumagalli, G., 2016. The role of scaffolding in physical activity in development of motor and cognitive skills. Journal of Sport \& Exercise Psychology, 38(Suppl), S20.

Tortella, P., \& Fumagalli, G., 2017. The effect of teaching methodologies in promoting physical and cognitive development in children. Physical Activity and Educational Achievement: Insights from Exercise Neuroscience, 297, 303-316. https://doi.org/10.4324/9781315305790-17

Tortella, P., Fumagalli, G., Coppola, R., Schembri, R., \& Pignato, S., 2019. The role of the educator/adult in supporting children of pre-school age in learning difficult tasks: the case of the Playground "Primo Sport 0246". Journal of Physical Education and Sport, 19(S5), 2015-2023.

Trulson, M.E., 1986. Martial arts training: a novel "cure" for juvenile delinquency. Human Relations, 39, 1131-1140. https://doi.org/10.1177/001872678603901204

Vygotsky, L.S., 1986. Thought and Language. Cambridge, MA, MIT Press.

Werchan, D. M., Collins, A. G., Frank, M. J., \& Amso, D. (2016). Role of Prefrontal Cortex in Learning and Generalizing Hierarchical Rules in 8-Month-Old Infants. The Journal of neuroscience: the official journal of the Society for Neuroscience, 36(40), 10314-10322. https://doi.org/10.1523/JNEUROSCl.1351-16.2016

\section{@(@) $\Theta \Theta$}

This work is licensed under a Attribution-NonCommercial-NoDerivatives 4.0 International (CC BY-NC-ND 4.0). 